\title{
Utilisation of chemically modified lampante oil for wood protection
}

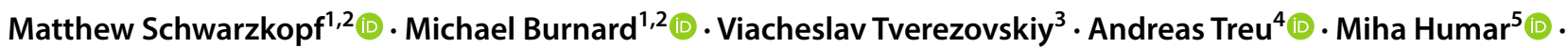 \\ Andreja Kutnar ${ }^{1,2}$ (])
}

Received: 26 February 2018 / Published online: 27 July 2018

(c) The Author(s) 2018

\begin{abstract}
Within the Slovenian region of Istria, the olive growing and oil production industry is strong. This industry has a long history and the olives grown here have high levels of biologically active compounds including a variety of phenolic compounds. Using residual materials generated by this industry in potential wood protection systems would not only valorise low-value materials and stimulate rural economies but would also provide an alternative to currently used oil-based protection systems. The objective of this study was to produce an oil treatment for wood protection and assess its efficacy in reducing leaching, weathering effects, and fungal decay. Two maleinisation techniques were used to chemically modify low-value lampante oil in an attempt to limit leaching when impregnated in wood. Pinus sylvestris (Scots pine) and Fagus sylvatica (European beech) were treated with the modified oils and underwent leaching, accelerated weathering, and decay tests. Leaching of the treatment oils was relatively low compared with other experiments and beech wood specimens treated with a direct maleinisation treatment showed improvement in performance compared to control specimens. In addition, it was found that the modified oils were not completely removed from the wood after solvent extraction indicating that they could potentially be used as an immobilisation agent in combination with other treatments thereby reducing the amount of active component of the protective agent.
\end{abstract}

\section{Introduction}

Olive and olive oil culture in the Istrian region of Slovenia has a long-established tradition dating back to the fourth century BC. The "Istrska belica" variety of olives (Istrian white olives) produced in Slovenian Istria has been praised for their ability to withstand low temperatures, high oil content, good taste, high levels of monounsaturated fatty acids, and their high levels of biologically active molecules including phenolic compounds, squalene, and tocopherols (Stark

Matthew Schwarzkopf

matthew.schwarzkopf@innorenew.eu

1 InnoRenew CoE, Livade 6, 6310 Izola, Slovenia

2 Andrej Marušič Institute, University of Primorska, Muzejski $\operatorname{trg}$ 2, 6000 Koper, Slovenia

3 BioComposites Centre, Bangor University, Bangor, Gwynedd LL57 2UW, UK

4 Norwegian Institute of Bioeconomy Research, Ås, Postboks 115, 1431 Akershus, Norway

5 Department of Wood Science and Technology, Biotechnical Faculty, University of Ljubljana, Rožina dolina, Cesta VIII/34, 1000 Ljubljana, Slovenia and Madar 2002). These characteristics may serve another purpose as well: providing protection against degradation in wood products. Development of alternative systems for wood protection is becoming of great importance, due to the ban of the many classic active ingredients in the European Union.

Direct use of extra virgin (EVOO) or virgin olive oil (VOO) as wood protection would prove to be an expensive option, however, less valuable products from olive production and the olive milling process also possess favourable characteristics. Much of this material is in the form of agricultural residue (e.g. leaves and branches) after beating and picking the olives or after seasonal olive tree pruning and would require further processing, extraction, and refinement before use (Jemai et al. 2008; Kiritsakis et al. 2010). Other options are lower quality oils including olive-pomace oil and lampante VOO. Olive-pomace oil is obtained from the residual paste from VOO production through treatments with solvents like hexane. A more readily usable material with no further processing needed is lampante oil (LO) produced during VOO production. $\mathrm{LO}$ is $\mathrm{VOO}$ that is not fit for human consumption and has undesirable organoleptic and/or chemical characteristics. This oil is typically further refined 
or used in technical applications (Aparicio and Harwood 2013). In addition to LO acting as a hydrophobic agent, it also contains phenolic compounds with antifungal properties that may inhibit the rate of growth in a range of fungi (Korukluoglu et al. 2008). It is well known that LO phenolic compounds are bioavailable and beneficially alter microbial activity and oxidative processes (Cicerale et al. 2012). With these desirable properties, $\mathrm{LO}$ has the potential to be utilized as a natural source of wood protection, particularly as an alternative to other oil-based protection systems currently in use (Hussain et al. 2013). However, using olive oil in a wood protection system is still a very limited field of study and the use of plant oils in general presents several challenges.

One of the largest challenges in using plant oils in a wood preservation system is the tendency for the oil to leach from the wood after treatment. Oil does not bond to the wood cell wall material, but rather being deposited on the surface within cell lumens. Limited oxygen levels in the wood slow the drying of the oil, keeping it in a liquid form and subject to exudation. To overcome these issues, chemical modification of a variety of plant oils has been investigated with positive results with respect to wood treatments (Treu et al. 2004; Terziev and Panov 2010; Temiz et al. 2013). Treu et al. (2004) conducted a screening study of modified linseed oils and found improved durability of treated wood with a variety of modifications. One promising modification was by maleinisation which uses maleic anhydride to bind the oil within the wood. This modification reacts maleic anhydride with the oil, targeting unsaturated bonds, and creating reactive sites that interact with wood hydroxyl groups. This helps fix the oil to the wood cell wall, rather than simply filling empty lumens. This modification has been investigated with other plant oils including soybean oil, rapeseed, hemp, and for other purposes including production of polymers (Mosiewicki et al. 2005). Based on the successes of these studies, two maleinisation methods were identified that could be viable for modifying LO to improve its viability for wood protection.

The objective of the present work was to develop and assess the efficacy of two experimental methodologies for the maleinisation of LO to be used for wood protection.

\section{Materials and methods}

The experimental approach was to produce two chemically modified LOs, impregnate wood specimens, and conduct a cursory examination of their performance regarding leaching, fungal decay resistance, and accelerated weathering.

LO was donated by the Institute for Olive Culture of Slovenia and was obtained from local sources in the Slovenian Istria region. Glycerol 99+\%; maleic anhydride $95 \%$; and hydroquinone $99 \%$ were obtained from Aldrich Chemical
(Darmstadt, Germany). The catalyst $p$-Toluenesulfonic acid monohydrate (PTSA) 98\%, was obtained from Alfa Aesar (Heysham, UK).

Wood specimens were prepared using the sapwood of Pinus sylvestris (Scots pine) and Fagus sylvatica (European beech).

A total of 80 leaching specimens were prepared with dimensions of $30 \mathrm{~mm} \times 30 \mathrm{~mm} \times 15 \mathrm{~mm}$ (longitudinal, tangential, radial). 40 specimens were prepared for each species, which were divided into four groups of ten that were then subjected to each of the four treatments (Table 1). 192 fungal decay resistance specimens were prepared with dimensions of $30 \mathrm{~mm} \times 10 \mathrm{~mm} \times 5 \mathrm{~mm}$ (longitudinal, tangential, radial). 96 specimens were prepared for each species, which were divided into four groups of 48 for each inoculum (two for each species). These four groups were again divided into four groups of ten for each treatment oil (18 for control). There were a total of 68 accelerated weathering test specimens prepared with dimensions of $75 \mathrm{~mm} \times 75 \mathrm{~mm} \times 15 \mathrm{~mm}$ (longitudinal, tangential, radial). 34 were prepared for each species.

\subsection{Synthesis of monoglyceride bis maleate half esters and diglyceride monomaleate half esters mixture}

The conditions for the reaction were adapted and optimized from the work of Mosiewicki et al. (2005) based on their maleinisation of linseed oil monoglycerides. This process consisted of a glycerolysis step followed by maleinisation (the resulting substance is referred to as GM).

\subsubsection{Glycerolysis of lampante oil}

Excess water (3.6 g) was first removed from the glycerol by heating at $150{ }^{\circ} \mathrm{C}$ for $1 \mathrm{~h}$ under a $\mathrm{N}_{2}$ atmosphere. The glycerolysis reaction was carried out in a $10 \mathrm{~L}$ reaction vessel with

Table 1 Factors and levels of experimental variables

\begin{tabular}{ll}
\hline Factors & Levels \\
\hline Wood Species & Pine \\
& Beech \\
Oil & Control_none \\
& Untreated lampante oil (LO) \\
& Glycerolysis/maleinisation (GM) \\
& Direct maleinisation (DM) \\
& Pine-Gloeopyllum trabeum (ZIML018) \\
& Pine—Rhodonia placenta (ZIM L033) \\
Fungus $^{\text {a }}$ & Beech-Trametes versicolor (ZIM L057) \\
& Beech—Pleurotus ostreatus (ZIM L030) \\
\hline
\end{tabular}

${ }^{a}$ Each species had two species-specific inoculants 
a mechanical stirrer, using a 1:1 molar ratio of oil (3800 g) to glycerol (388 g). PTSA (42 g) was used as a catalyst (1\% $\mathrm{wt})$ and hydroquinone $(2.1 \mathrm{~g})$ was added as a free radical inhibitor (500 ppm). A vacuum was applied to remove any dissolved air and the reaction vessel was back filled with $\mathrm{N}_{2}$. The mixture was stirred at $200 \mathrm{rpm}$ and reacted for five hours. The reaction was monitored by taking samples every hour for NMR analysis. The stirrer was then shut off and the reaction was heated overnight at $60{ }^{\circ} \mathrm{C}$.

\subsubsection{Maleinisation}

Using a 1.5:1 weight ratio of the glyceride/glycerol mixture to maleic anhydride, and targeting a $95 \%$ maleinisation, maleic anhydride $(1108 \mathrm{~g})$ was added to the mixture in three steps at $20 \mathrm{~min}$ intervals at $60^{\circ} \mathrm{C}$, with stirring at $200 \mathrm{rpm}$, and held under a $\mathrm{N}_{2}$ atmosphere. The mixture was then heated at $80^{\circ} \mathrm{C}$ for four hours and raised to $120^{\circ} \mathrm{C}$ for 2 more hours. The reaction was monitored with NMR analysis by taking samples every hour for $5 \mathrm{~h}$. The contents were then held overnight at $60{ }^{\circ} \mathrm{C}$. The final product was a dark viscous liquid that was stored in airtight containers.

\subsection{Synthesis of maleated lampante oil}

Maleic anhydride (646 g) was added to the preheated steel reactor $\left(70{ }^{\circ} \mathrm{C}\right)$. The maleic anhydride was melted after which LO (4530 g) was added, targeting $40 \%$ maleinisation. The targeted temperature was then increased to $200{ }^{\circ} \mathrm{C}$ and stirred at $200 \mathrm{rpm}$. Samples were taken every hour for $6 \mathrm{~h}$ after which the reaction was stopped and cooled. The final product was stored in airtight containers. This process, unlike the first modified oil was directly maleated (the resulting substance is referred to as DM).

\subsection{Characterisation of oils}

Samples were taken every hour during reactions and ${ }^{1} \mathrm{H}-$ NMR spectra were recorded using an Ultrashield 400 Plus (400 MHz) (Bruker; Coventry, UK) using deuterated chloroform $\left(\mathrm{CDCl}_{3}\right)$ as a solvent to monitor the reactions. Viscosity of the modified oil and intermediate products was measured using a Model DV-II viscometer (Brookfield; Essex, UK) with a S-62 spindle.

\subsection{Wood impregnation process and testing}

All wood specimens were cut to their designated dimensions, submerged in their respective oil treatment, and were impregnated in one batch in a pressure vessel using the same process. A full-cell treatment was used in which the oil was heated at $60{ }^{\circ} \mathrm{C}$, a vacuum of 0.04 bar was applied for $1 \mathrm{~h}$, and then pressurized at 7.8 bar for $2 \mathrm{~h}$. Specimens were then removed and excess oil was wiped from the surface. Specimens were weighed, and their dimensions were measured before and after impregnation. Uptake was calculated as the weight change divided by the volume of the specimen and expressed in $\mathrm{kg} \mathrm{m}^{-3}$.

\subsection{Leaching}

Resistance of the impregnated oils to leaching was assessed by subjecting specimens (Tables 1 and 2) $(30 \mathrm{~mm} \times 30 \mathrm{~mm} \times 15 \mathrm{~mm})$ to wet-dry cycles consisting of $48 \mathrm{~h}$ of submersion in distilled water, and $24 \mathrm{~h}$ of drying in a conditioning chamber at $40{ }^{\circ} \mathrm{C}$ and $40 \% \mathrm{RH}$. This procedure was repeated four times. Mass change was recorded throughout each cycle. Leaching tests were conducted in two experimental blocks, each with five replicates per species per treatment. Leaching was defined as the change in mass between the original specimens and leached specimens.

\subsection{Fungi Tests}

Fungi tests were performed using mini blocks $(30 \mathrm{~mm} \times 10 \mathrm{~mm} \times 5 \mathrm{~mm})$ following the procedure defined by Bravery (1980), for a duration of 16 weeks, and exposed to both brown rot and white rot fungi. Pine specimens were exposed to Gloeopyllum trabeum (GT) (ZIM L018) and Rhodonia placenta (RP) (ZIM L033) brown rot fungi, and beech specimens were exposed to Trametes versicolor (TV) (ZIM L057) and Pleurotus ostreatus (PL) (ZIM L030) white rot fungi. The fungal isolates originated from the fungal collection of the Biotechnical Faculty at the University of Ljubljana (Raspor et al. 1995). Specimens were first dried, then inoculated with their respective fungi for 16 weeks. At the end of the exposure period, specimens were cleaned

Table 2 Factor combinations, treatments, and observations

\begin{tabular}{lll}
\hline Factors and combinations & $\begin{array}{l}\text { No. of treat- } \\
\text { ments }\end{array}$ & $\begin{array}{l}\text { No. of observa- } \\
\text { tions per treat- } \\
\text { ment }\end{array}$ \\
\hline Leaching & & \\
$\quad$ Species & 2 & 40 \\
$\quad$ Oil & 4 & 10 \\
Fungal tests & & \\
Species & 2 & 96 \\
Oil & 4 & 48 \\
Inoculum & 4 & $10^{\mathrm{a}}$ \\
Accelerated weathering & & 34 \\
$\quad$ Species & 2 & $9^{\mathrm{b}}$ \\
Oil & 4 & \\
\hline
\end{tabular}

${ }^{\mathrm{a}}$ There were 18 control specimens

${ }^{\mathrm{b}}$ For GM treatment, there were only seven specimens per species 
and dried. Relative mass loss was calculated by taking the pre-inoculation dry weight minus the dry weight after an incubation time of 16 weeks, divided by the pre-inoculation dry weight.

After the fungal exposure, the same specimens had the oil extracted. For oil extraction, a Büchi B-811 (Büchi Labortechnik AG 2006) automated extraction system was used. Samples were extracted with a cyclohexane-ethanol mixture for $40 \mathrm{~h}$. The mass of oil extracted by the dry weight after an incubation time of 16 weeks was divided to calculate the relative amount of oil extracted. This was used as another measure of oil immobilisation/leaching.

Moisture content (MC) was also recorded before inoculation and after fungi tests.

\subsection{Accelerated weathering}

One cycle of the European standard, EN 927-6 (2006), in a Q-Labs (Saarbrücken, Germany) QUV Spray RP weathering tester, was used. This cycle consists of four stages: (1) $24 \mathrm{~h}$ of heat $\left(45^{\circ} \mathrm{C}\right)$ and condensation; (2) $2.5 \mathrm{~h}$ of UV light at $60{ }^{\circ} \mathrm{C}$; (3) $0.5 \mathrm{~h}$ deionised water spray; (4) repeat stages 2 and 3, 48 times. One cycle runs for a total of $168 \mathrm{~h}$ (1 week). Specimen dimensions were $75 \mathrm{~mm} \times 75 \mathrm{~mm} \times 15 \mathrm{~mm}$.

Before and after exposure to weathering, specimens were weighed and colour measurements in the CIE $L^{*} \mathrm{a}^{*} b^{*}$ colour space were made using an Erichsen EasyCo 566 device (Hemmer, Germany) on three points of the exposed specimen surface (lower left, middle, and upper right).

\subsection{Data and statistical analyses}

Data and statistical analyses were conducted in R, (version 3.4.1, R Core Team 2017), using RStudio (version 1.0.153, RStudio Inc. 2017). Figures were created using the ggplot 2 $R$ package (Wickham 2009). A complete record of the analyses and the data are available as supplemental material (Burnard et al. 2018).

The assumptions for parametric significance tests of homogeneity of variance and normally distributed data were not met for the leaching data, fungi tests, or accelerated weathering tests. Instead, non-parametric tests were used to test for significant differences between treatments and to determine effect sizes. The Wilcoxon rank sum test was used to test for significant differences when comparing two levels of a factor, and the Kruskal-Wallis rank sum test was used to test for differences when comparing more than two levels of a factor. The Kruskal-Wallis rank sum can determine if population distributions are identical but does not provide a direct method for determining effect size. When the Kruskal-Wallis rank sum test indicated non-identical distributions were present, the Wilcoxon rank sum test was used to inspect differences between all treatment combinations, determine effect sizes, and confidence intervals. The effect size returned by this method is the median difference between each observation of one factor level and each observation from another level of the same factor. This value was interpreted as an indication of the difference in performance between treatments. Differences are reported as significant when $p<0.05$.

\section{Results and discussion}

\subsection{Synthesis of GM}

The product became gradually darker and more viscous throughout the glycerolysis reaction. The initial state of the reaction had a viscosity of $70 \mathrm{cP}$ and increased to $153 \mathrm{cP}$. The NMR results (Fig. 1) of the final product from the reaction showed that there was a reduction in the amount of triglycerides (5.2 ppm) and that the glycerol reacted with the LO to form a mixture of compounds (3.4-4.4 ppm).

During the second step of maleinisation, the product became much more viscous $(650 \mathrm{cP})$. NMR results in Fig. 2 showed a reduction in the amount of non-reacted maleic anhydride at $7 \mathrm{ppm}$. However, the signal at $7 \mathrm{ppm}$ was not completely removed indicating that there was still unreacted maleic anhydride.

\subsection{Synthesis of DM}

Throughout the reaction the product became slightly darker but had a viscosity close to that of the original LO. NMR results in Fig. 3 showed that the maleic anhydride signal at $7 \mathrm{ppm}$ was reduced and was almost entirely consumed during the reaction.

\subsection{Wood impregnation}

The relative uptake achieved during the impregnation process was near $380 \mathrm{~kg} \mathrm{~m}^{-3}$ for beech and $430 \mathrm{~kg} \mathrm{~m}^{-3}$ for pine (Table 3). The relative uptakes indicate that the wood was fully treated with the respective oil treatments. The difference between pine and beech wood can be explained with the density. Beech wood has a higher density than pine and has less voids available for filling with oil.

Specimens treated with the GM oil had the darkest appearance while the DM and LO oils had similar appearances (Fig. 4). 
Fig. 1 NMR results of the glycerolysis step of GM synthesis comparing the initial state of the reaction to the final state at $300 \mathrm{~min}$. The area between 3 and $6 \mathrm{ppm}$ is magnified to show changes in glycerol moieties and reduction of triglycerides
Fig. 2 NMR results of the maleinisation step of GM synthesis before and after maleinisation at $300 \mathrm{~min}$. The region between 3 and $7.1 \mathrm{ppm}$ was selected to see in greater detail the reduction in maleic anhydride and avoid the solvent peak at $7.2 \mathrm{ppm}$
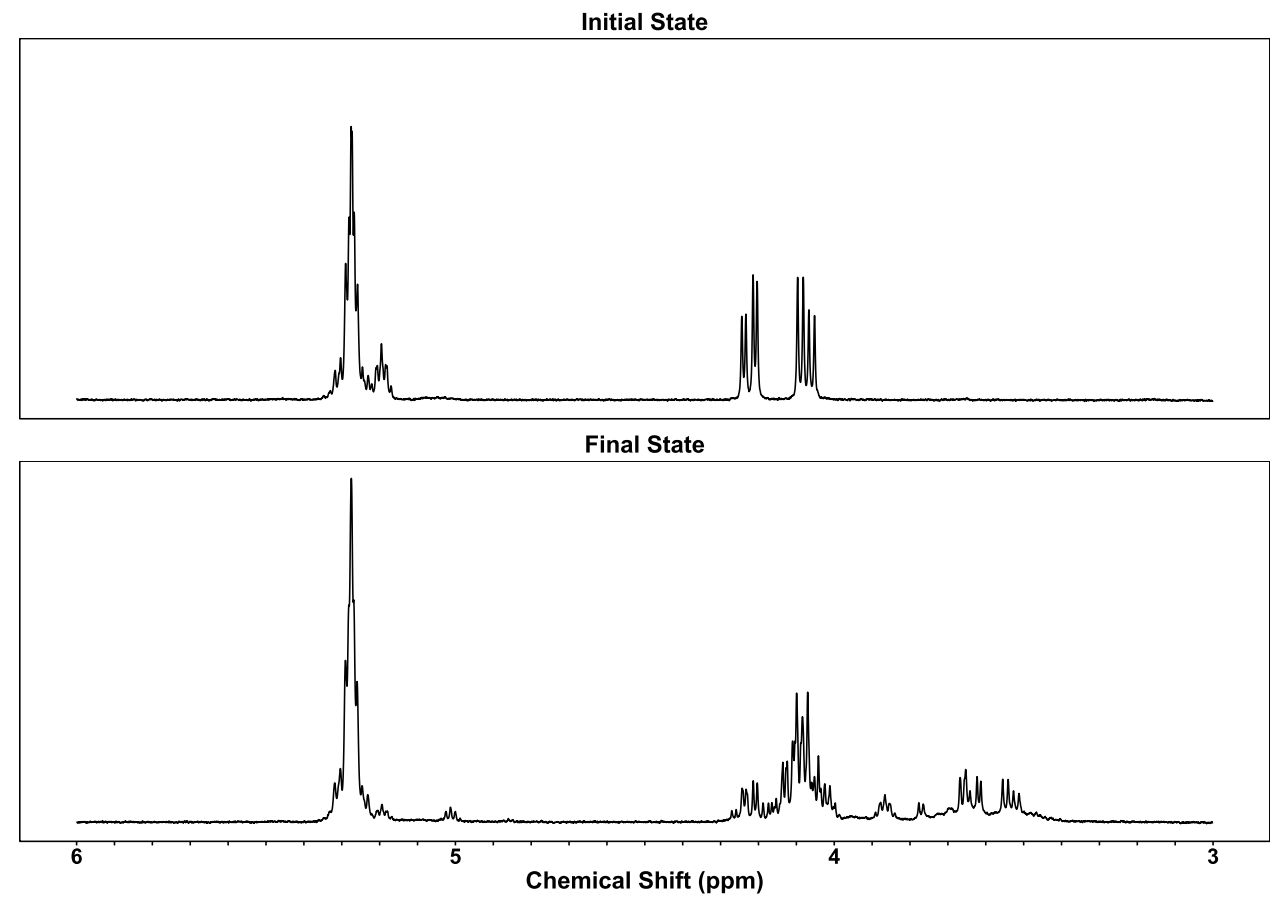

Initial State

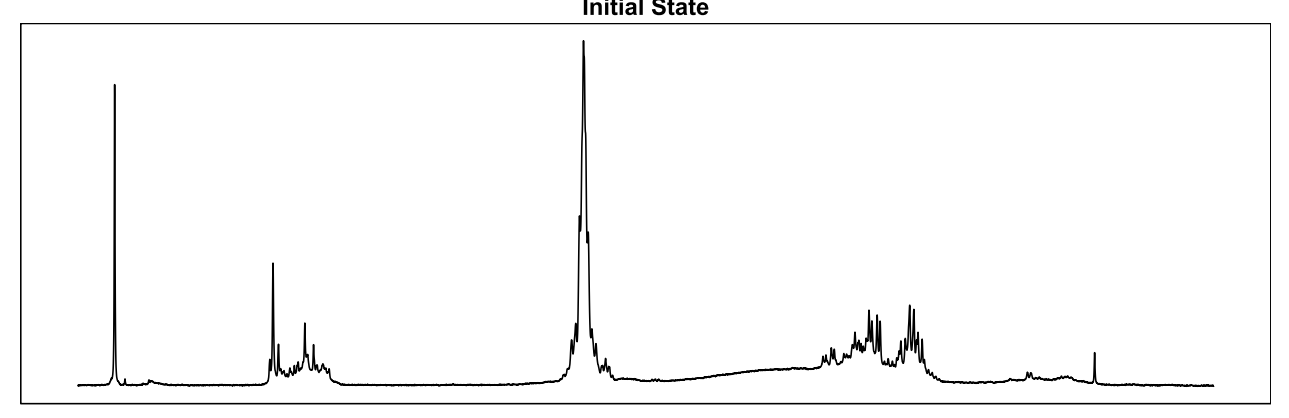

Final State

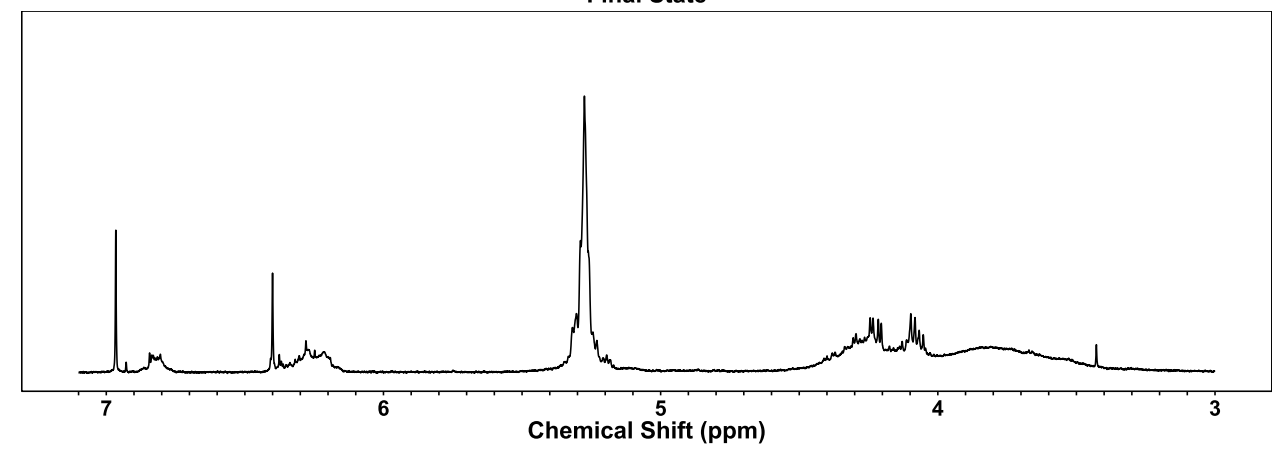

\subsection{Leaching}

Wood in outdoor applications is frequently exposed to weathering, hence leaching resistance is one of the important performance parameters. To assess this parameter, the relative mass change between the leaching cycles and the starting weight was monitored (Table 4). Beech wood specimens treated with GM lost the most mass (44.7\%), followed by DM treated specimens (18.1\%). For pine, GM treated specimens lost the most mass (22.6\%). There was no significant difference in mass loss between experimental test blocks. In both beech and pine specimens, specimens treated with non-modified LO had an initial increase in mass which was unexpected. In all cases except that of pine specimens treated with LO, the final absolute weight change reflected a loss. These unexpected increases in mass may be related to water-oil interactions within the wood structure, but at this time it was not possible to determine this. 
Fig. 3 NMR results of DM synthesis comparing the initial state of the reaction to that final state at $300 \mathrm{~min}$
Initial State

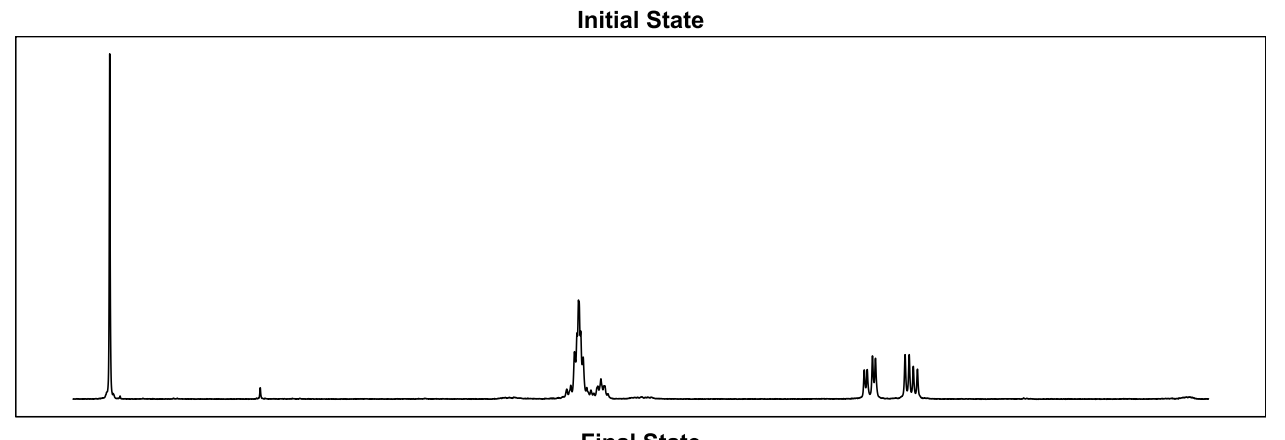

Final State

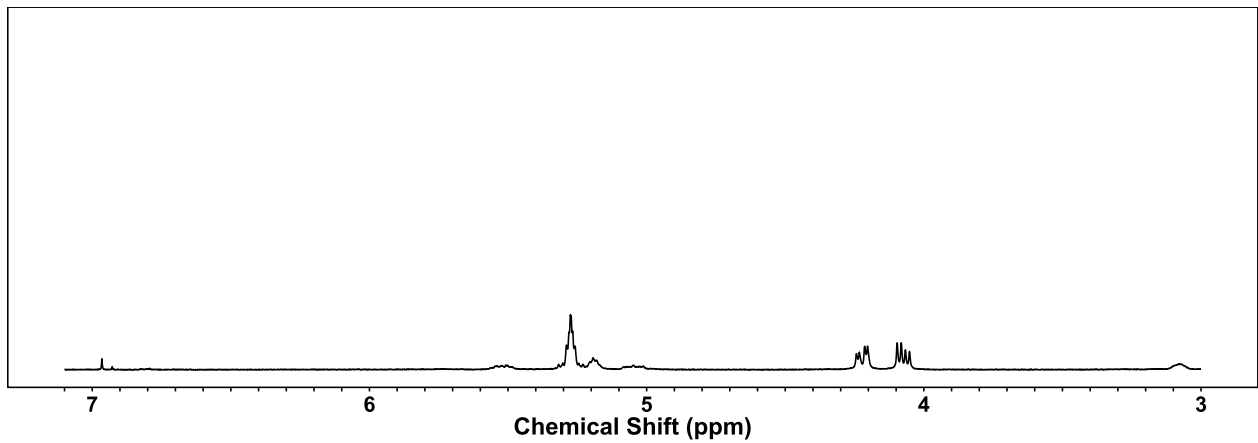

Table 3 Average ( \pm one standard deviation) net uptake of beech and pine wood specimens treated with LO and modified variants

\begin{tabular}{lll}
\hline Oil treatment & Beech $\left(\mathrm{kg} \mathrm{m}^{-3}\right)$ & Pine $\left(\mathrm{kg} \mathrm{m}^{-3}\right)$ \\
\hline LO & $374 \pm 13$ & $447 \pm 57$ \\
DM & $396 \pm 15$ & $457 \pm 55$ \\
GM & $368 \pm 75$ & $392 \pm 100$ \\
\hline
\end{tabular}

There were 60 replicates for each species-oil combination

Comparisons were made between treatment types and summary data is found in Table 5. The median mass difference of oil-treated beech wood samples was significantly different for all combinations except control and $\mathrm{LO}$ ( $p$ value $0.579,95 \% \mathrm{CI}-0.1$ to $0.3 \%$ ). However, there were significant differences in weight change between all other comparisons. GM treated specimens lost close to $3 \%$ more weight than specimens treated with LO ( $p$ value $<0.001$, 95\% CI 1.1-4.4\%). Control specimens also lost close to $2.5 \%$ more weight than GM specimens ( $p$ value $<0.001$, 95\% CI 1.0-4.3\%). DM treated specimens lost close to $1.5 \%$ more weight than GM specimens ( $p$ value 0.005 , 95\% CI $0.2-3.4 \%)$ and $1 \%$ more than LO treated specimens ( $p$ value $<0.001,95 \%$ CI $0.7-1.2 \%$ ). Control specimens lost close to $1 \%$ more weight than DM specimens ( $p$ value $<0.001,95 \%$ CI $0.6-1.1 \%$ ).

Fig. 4 Comparison of pine (top row) and beech (bottom row) specimens treated with nonmodified and modified oils

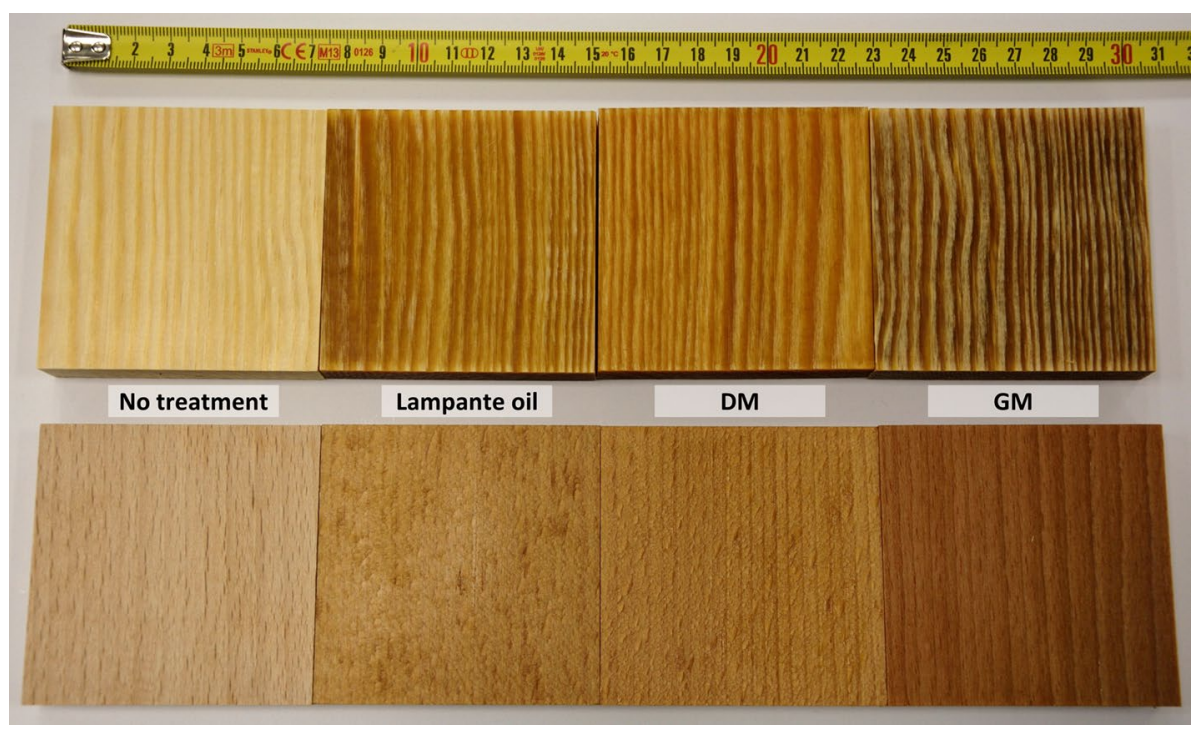


Table 4 Relative mass changes throughout leaching cycles for each treatment

\begin{tabular}{llrrrr}
\hline Species & Treatment & \multicolumn{3}{c}{ Relative mass (\%) } & \\
\cline { 3 - 6 } & & Cycle 1 & Cycle 2 & Cycle 3 & Cycle 4 \\
\hline \multirow{2}{*}{ Beech } & Control & -2.4 & -1.8 & -1.7 & -3.1 \\
& LO & 7.5 & 5.7 & 1.3 & -3.4 \\
& DM & -1.2 & -11.1 & -6.8 & -18.1 \\
& GM & -4.2 & -34.1 & -40.4 & -44.7 \\
Pine & Control & -7.3 & -2.9 & -5.2 & -4.4 \\
& LO & 16.7 & 21.0 & 20.9 & 18.2 \\
& DM & 9.6 & 2.9 & -1.5 & 0.2 \\
& GM & -5.5 & -20.8 & -23.2 & -22.6 \\
\hline
\end{tabular}

Table 5 Median difference between relative mass loss for listed treatment group comparisons

\begin{tabular}{|c|c|c|c|c|c|}
\hline Species & $\begin{array}{l}\text { Compari- } \\
\text { son }\end{array}$ & $\begin{array}{l}\text { Median } \\
\text { mass } \\
\text { difference } \\
(\%)\end{array}$ & Lower CI & Upper CI & $p$ value \\
\hline \multirow[t]{6}{*}{ Beech } & $\begin{array}{l}\text { LO-con- } \\
\text { trol }\end{array}$ & 0.1 & -0.1 & 0.3 & 0.579 \\
\hline & $\begin{array}{l}\text { DM-con- } \\
\text { trol }\end{array}$ & 0.8 & 0.6 & 1.1 & $<0.001 * * *$ \\
\hline & LO-DM & 0.9 & 0.7 & 1.2 & $<0.001 * * *$ \\
\hline & GM-DM & 1.7 & 0.2 & 3.4 & $0.005^{* *}$ \\
\hline & $\begin{array}{l}\text { GM-con- } \\
\text { trol }\end{array}$ & 2.7 & 1.0 & 4.3 & $<0.001 * * *$ \\
\hline & LO-GM & 2.8 & 1.1 & 4.4 & $<0.001 * * *$ \\
\hline \multirow[t]{6}{*}{ Pine } & $\begin{array}{l}\text { DM-con- } \\
\text { trol }\end{array}$ & 0.7 & 0.0 & 0.9 & 0.063 \\
\hline & $\begin{array}{l}\text { GM-con- } \\
\text { trol }\end{array}$ & 0.9 & 0.4 & 1.5 & $0.007 * *$ \\
\hline & LO-DM & 1.1 & 0.8 & 1.7 & $<0.001 * * *$ \\
\hline & GM-DM & 1.5 & 0.9 & 1.9 & $<0.001 * * *$ \\
\hline & $\begin{array}{l}\text { LO-con- } \\
\text { trol }\end{array}$ & 1.7 & 1.3 & 2.4 & $<0.001 * * *$ \\
\hline & LO-GM & 2.6 & 2.2 & 3.2 & $<0.001 * * *$ \\
\hline
\end{tabular}

For pine, median weight loss differences were significant for all combinations except control and DM ( $p$ value $0.063,95 \%$ CI $0.0-0.9 \%$ ). However, there were significant differences in weight change between all other comparisons. GM treated specimens lost approximately $2.5 \%$ more weight than LO treated specimens ( $p$ value $<0.001,95 \%$ CI $2.2-3.2 \%)$. Control specimens lost approximately $1.5 \%$ more weight than those treated with LO ( $p$ value $<0.001$, 95\% CI 1.3-2.4\%). DM treated specimens lost $1.5 \%$ more weight than GM treated specimens ( $p$ value $<0.001,95 \%$ CI $0.9-1.9 \%)$ and $1 \%$ more than LO treated specimens ( $p$ value $<0.001,95 \%$ CI $0.8-1.7 \%)$. Control specimens lost $1 \%$ more weight than GM treated specimens ( $p$ value
0.007, 95\% CI 0.4-1.5\%). The small effect sizes and large relative variances make it difficult to say that one treatment was better than the other. However, the trend was the same in both beech and pine with LO treated specimens performing better (leaching less) than other treatments, followed by GM, DM, and control specimens performed the poorest. In this experiment, leaching was low in general compared with previous reports on oil leaching in wood (Alfredsen et al. 2004; Swaboda et al. 2016).

The data indicate the relative leachability of the respective oils in above ground (use class 3) applications, since the method used was not the most severe one and was mild compared with other procedures such as EN 84 or accelerated weathering that affects leaching (Habicht et al. 2003).

With this in mind, a second method was used to determine the level of oil immobilised in wood. Blocks exposed to the fungal tests were solvent extracted to remove remaining oil within the wood structure. Any remaining mass other than wood would be oil that was fixed within the wood and difficult to remove. This allowed for a side by side comparison of the leaching resistance of the oil treatments used in this study.

The amount of oil that was extracted from the specimens during the solvent extraction procedure is summarized in Table 6. The most oil was extracted from DM treated beech wood specimens, followed by LO, and finally GM treated specimens with the least oil extracted. LO treated pine wood specimens had the highest mean values for extracted oil, followed by DM, and with GM at the lowest. This comparison between treatments indicated that GM treated oil specimens had more oil immobilised within the wood structure.

The inability of solvent extraction to completely remove the oils indicates that they could potentially be used as immobilisation agents in combination with other treatments such as impregnation with wood preservatives and thereby reduce the amount of active component of the protective agent (Liibert et al. 2011; Tomak et al. 2011; Treu et al. 2011). However, the motivation for using olive oil-based

Table 6 Relative amount of oil extracted using solvent extraction

\begin{tabular}{llll}
\hline Species & Treatment & Mass loss (\%) & $\begin{array}{l}\text { Standard } \\
\text { deviation }\end{array}$ \\
\hline Beech & LO & 14 & $(10)$ \\
& DM & 26 & $(4)$ \\
& GM & 13 & $(3)$ \\
Pine & LO & 40 & $(9)$ \\
& DM & 39 & $(10)$ \\
& GM & 26 & $(11)$ \\
\hline
\end{tabular}

Values represent means of 20 replicates. Values in parentheses are one standard deviation 
products in this study was to make the use of biocides unnecessary and utilise low-grade agricultural residues.

\subsection{Fungi tests}

Summary data of relative mass loss is given in Table 7 grouped by fungus and wood species. Mass losses of the control wood specimens indicate that the fungal strains applied were active.

Figure 5 shows the relative mass losses for beech specimens exposed to different fungi. Beech, control specimens had median relative mass losses of 19 and $36 \%$ for Pleurotus ostreatus and Trametes versicolor, respectively. For specimens inoculated with Pleurotus ostreatus, there was a significant difference between DM treated specimens and all others ( $p$ values $<0.002$ ). When inoculated with Trametes versicolor, DM treated specimens had significant differences with control and GM specimens ( $p$ values $<0.001$ ), but not LO. However, by comparison for oil treatments, LO had a large standard deviation. DM treated specimens for Pleurotus ostreatus and Trametes versicolor had the lowest median relative mass loss at 10 and $12 \%$, respectively.

Figure 6 shows the relative mass loss for pine specimens exposed to different fungi. Pine, control specimens had median relative mass losses of 14 and $18 \%$ for Gloeopyllum trabeum and Rhodonia placenta, respectively. For specimens inoculated with Gloeopyllum trabeum and treated with DM, there were significant differences in the relative median mass loss with GM and
LO oils ( $p$ values $<0.004$ ). There was also a significant difference between GM and LO ( $p$ value $<0.001$ ), and Control and LO treated specimens ( $p$ value $=0.040)$. For specimens inoculated with the Rhodonia placenta inoculant, there was a significant difference between DM treated specimens and all other treatments ( $p$ value $<0.018$ ), but no other significant differences between treatments. LO treated specimens with the Gloeopyllum trabeum inoculant and DM treated specimens with the Rhodonia placenta inoculant had the lowest median relative mass loss at 7 and $10 \%$, respectively.

While statistical differences between treatments were found, the treatments with the lowest mass losses would still have a significant effect on physical properties. Subsequent mechanical testing of specimens could help determine if the wood material has really undergone losses in strength. In future tests, it is aimed to impregnate the wood with much lower concentrations of the treated oils rather than saturating the specimens. This would provide us with a more realistic view of the antimicrobial and fungal performance of the wood/oil treatment specimens rather than simply creating a hydrophobic oil barrier. However, recent studies clearly indicate that water exclusion efficacy contributes to the overall performance of wood in outdoor applications (Meyer-Veltrup et al. 2017) and the hydrophobic effect cannot be neglected. Additionally, the effect of oil products in culture media on fungal growth could be investigated, where radial growth in a Petri dish is recorded (Paajanen and Ritschkoff 2002).

Table 7 Relative mass loss after fungal exposure separated by wood species, fungus, and treatment

\begin{tabular}{|c|c|c|c|c|c|c|c|}
\hline Species & Inoculant & Treatment & $\begin{array}{l}\text { Relative mass loss, } \\
\text { mean }(\%)\end{array}$ & $\begin{array}{l}\text { Relative mass loss, } \\
\text { median (\%) }\end{array}$ & $\begin{array}{l}\text { Standard devia- } \\
\text { tion }(\%)\end{array}$ & $\begin{array}{l}\text { MC after } 16 \text { week } \\
\text { incubation (\%) }\end{array}$ & $\begin{array}{l}\text { No. of } \\
\text { observa- } \\
\text { tions }\end{array}$ \\
\hline \multirow[t]{8}{*}{ Beech } & \multirow[t]{4}{*}{ PL } & Control & 23 & 19 & 11 & 82 & 18 \\
\hline & & LO & 21 & 21 & 8 & 39 & 10 \\
\hline & & $\mathrm{DM}$ & 10 & 10 & 2 & 37 & 10 \\
\hline & & GM & 23 & 24 & 3 & 70 & 10 \\
\hline & \multirow[t]{4}{*}{ TV } & Control & 34 & 36 & 15 & 82 & 18 \\
\hline & & LO & 22 & 20 & 12 & 39 & 10 \\
\hline & & DM & 13 & 12 & 3 & 42 & 10 \\
\hline & & GM & 29 & 29 & 1 & 78 & 10 \\
\hline \multirow[t]{8}{*}{ Pine } & \multirow[t]{4}{*}{ GT } & Control & 27 & 14 & 27 & 113 & 18 \\
\hline & & LO & 8 & 7 & 3 & 28 & 10 \\
\hline & & $\mathrm{DM}$ & 12 & 12 & 2 & 29 & 10 \\
\hline & & GM & 26 & 27 & 8 & 75 & 10 \\
\hline & \multirow[t]{4}{*}{$\mathrm{RP}$} & Control & 19 & 18 & 10 & 59 & 18 \\
\hline & & LO & 18 & 18 & 4 & 34 & 10 \\
\hline & & $\mathrm{DM}$ & 11 & 10 & 3 & 22 & 10 \\
\hline & & GM & 18 & 18 & 5 & 55 & 10 \\
\hline
\end{tabular}


Fig. 5 Relative mass loss for beech specimens, grouped by inoculant

Fig. 6 Relative mass loss for pine specimens, grouped by inoculant
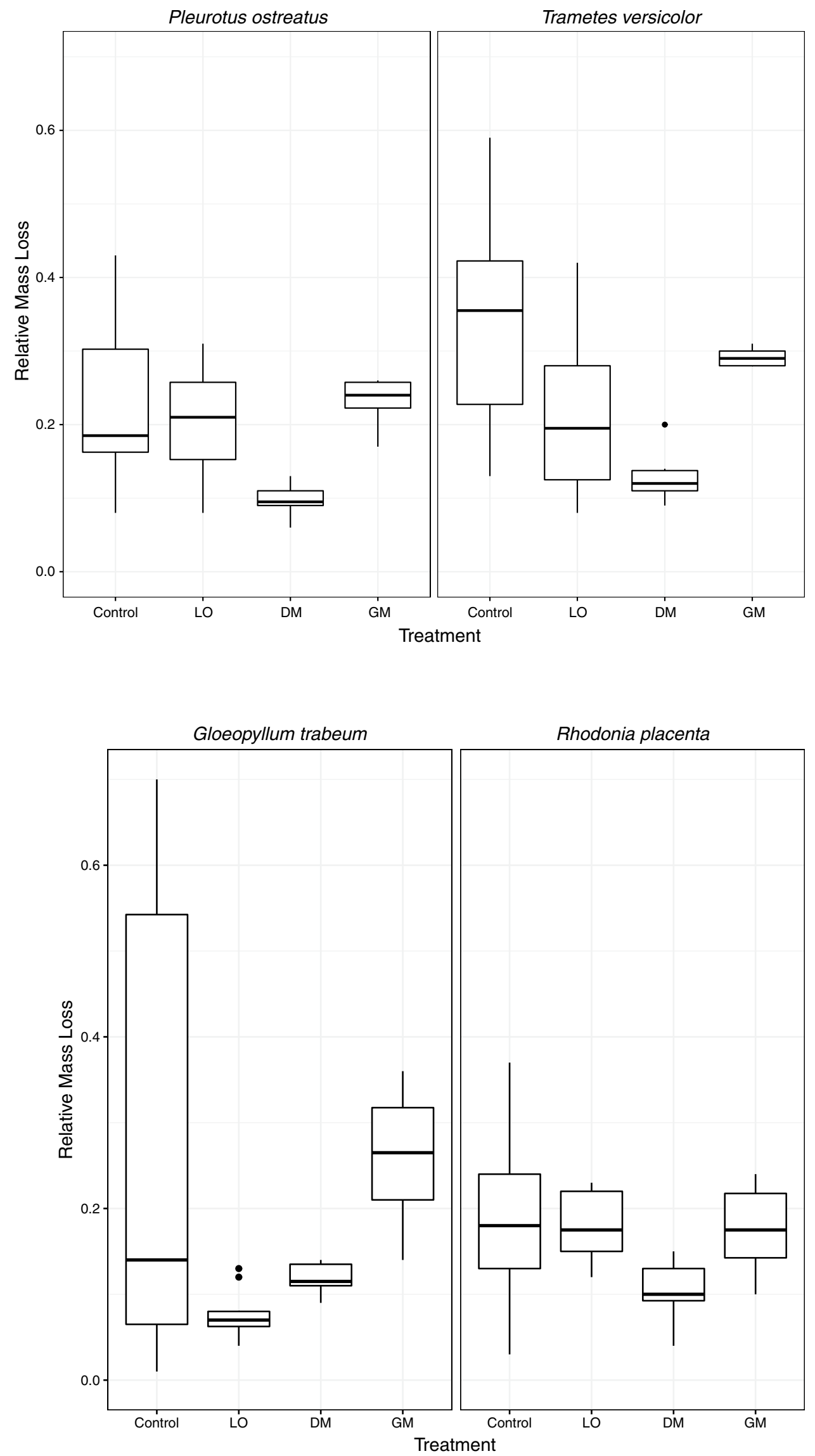


\subsubsection{Wood moisture content}

Both pine and beech specimens had an average MC of $9 \%$ before inoculation. Post incubation MC values can be seen in Table 7. As expected, post incubation MC was the highest in control specimens of both species ranging from 59 to 113\%. GM treated specimens for both wood species and all fungi had the highest MC levels. For PL inoculated beech specimens, GM treated specimens had the highest MC at $70 \%$, followed by LO (39\%), and DM had the lowest MC at $37 \%$. TV inoculated, GM treated beech specimens had a MC of $78 \%$, followed by DM (42\%), and LO had the lowest $\mathrm{MC}$ at $39 \%$. For GT inoculated pine specimens, GM had the highest MC at 75\%, followed by DM and LO (29 and 28\%, respectively). For RP inoculated pine specimens, GM had the highest MC at 55\% followed by LO and DM (34 and $22 \%$, respectively).

The MC at the end of fungal exposure was within the required MC according to the European standard EN 113. However, it could not be determined at which point of time the wood moisture content was reaching a sufficient level for the fungi. Critical moisture conditions for fungal decay are shown to be slightly below fibre saturation point of untreated wood material in a pile test. Beech samples, however, have much lower MC minima and the white rot can still degrade the material (Meyer et al. 2016). The Bravery and EN 113 tests are designed to determine the toxic value of different concentrations of wood preservatives and not for assessing moisture exclusion treatments. Excluding moisture from wood in long-term outside applications can be achieved by hydrophobic substances such as oils and waxes (Borgin and Corbett 1970).

Capillary water uptake is assumed to be very low for oil treated wood significantly reducing wetting ability. This property could be used to predict field performance of wood (Meyer-Veltrup et al. 2017). However, the absence of a biocidal effect from the oil treatment makes long-term durability unlikely.

\subsection{Accelerated weathering}

Before and after weathering, the colour of the specimens was measured. Table 8 provides a summary of these measured values. The values listed are an average of CIE $L^{*} a^{*} b^{*}$ values. The last two columns show the estimated colour that was converted from CIE $L^{*} a^{*} b^{*}$ values to hexadecimal format.

Table 9 shows the differences between measurements. In these measurements with beech specimens of all treatments, the lightness value $\left(L^{*}\right)$ decreased, and the specimens became darker. In pine, the control specimens became darker, but the specimens with an oil treatment became more lightly coloured. The terms " $a$ " " and " $b$ " describe the green-red and blue-yellow opponent colour relationship, respectively. The term $\Delta E$ is used to quantify the difference

Table 8 Colour measurements before and after accelerated weathering. The colours in the last two rows were generated using the hexadecimal identifier listed

\begin{tabular}{|c|c|c|c|c|c|c|c|c|c|}
\hline \multirow{2}{*}{ Species } & \multirow{2}{*}{ Treatment } & \multicolumn{3}{|c|}{ Colour before } & \multicolumn{3}{|c|}{ Colour after } & \multirow{2}{*}{$\begin{array}{l}\text { Pre } \\
\text { colour }\end{array}$} & \multirow{2}{*}{$\begin{array}{l}\text { Post } \\
\text { colour }\end{array}$} \\
\hline & & $L^{*}$ & $a^{*}$ & $\mathbf{b}^{*}$ & $\mathbf{L}^{*}$ & $a^{*}$ & $\mathbf{b}^{*}$ & & \\
\hline \multirow{4}{*}{ Beech } & Control & 71.79 & 6.92 & 14.46 & 69.42 & 7.94 & 15.44 & \#С5АВ96 & \#BFA48E \\
\hline & LO & 57.80 & 12.11 & 23.51 & 46.79 & 18.27 & 24.04 & \#AA8262 & \#946347 \\
\hline & $\mathrm{DM}$ & 55.05 & 14.50 & 28.00 & 49.01 & 18.05 & 24.04 & \#A87A54 & \#9A684D \\
\hline & GM & 53.57 & 15.05 & 22.91 & 41.00 & 16.02 & 17.19 & \#A37659 & \#805645 \\
\hline \multirow{5}{*}{ Pine } & Control & 78.25 & 5.67 & 22.58 & 70.89 & 10.26 & 22.86 & \#D9BD98 & \#CBA684 \\
\hline & LO & 52.24 & 9.46 & 22.44 & 57.42 & 9.79 & 23.82 & \#977657 & \#A58361 \\
\hline & & & & & & & & & \\
\hline & DM & 50.03 & 13.07 & 27.18 & 51.69 & 12.80 & 22.96 & \#986E49 & \#997354 \\
\hline & GM & 53.27 & 8.25 & 20.52 & 54.24 & 14.54 & 24.04 & \#977A5C & \#A37859 \\
\hline
\end{tabular}

*Values are the mean of 9 replicates, except GM which had 7. 
Table 9 Differences in colour measurements before and after accelerated weathering

\begin{tabular}{llrrrr}
\hline Species & Treatment & \multicolumn{5}{c}{ Colour change } \\
\cline { 3 - 6 } & & \multicolumn{1}{c}{$L^{*}$} & \multicolumn{1}{c}{$a^{*}$} & \multicolumn{1}{c}{$b^{*}$} & \multicolumn{1}{c}{$\Delta E$} \\
\hline \multirow{2}{*}{ Beech } & Control & -2.37 & 1.01 & 0.98 & 2.76 \\
& LO & -11.01 & 6.16 & 0.53 & 12.62 \\
& DM & -6.04 & 3.55 & -3.96 & 8.05 \\
& GM & -12.57 & 0.97 & -5.72 & 13.85 \\
Pine & Control & -7.35 & 4.59 & 0.28 & 8.67 \\
& LO & 5.19 & 0.33 & 1.38 & 5.37 \\
& DM & 1.66 & -0.27 & -4.22 & 4.54 \\
& GM & 0.97 & 6.28 & 3.52 & 7.26 \\
\hline
\end{tabular}

Negative $L^{*}$ values indicate darkening and positive values indicate lightening

or distance between two colours. A $\Delta E$ result is typically considered to be equivalent to the human eye.

From these measurements, beech wood specimens treated with an oil underwent larger colour change than pine wood specimens. LO and GM treated beech changed the most ( $\Delta E=12.62$ and 13.85 , respectively). Both of these treatments showed more darkening than others $\left(\Delta L^{*}=11.01\right.$ and 12.57 , respectively).

The expectation was that all specimens would become lighter after weathering, but it is believed that the darkening of the wood surface can be ascribed to the fact that there are dark coloured quinone compounds formed on the surface of the wood (Hon and Shiraishi 2001). These compounds are usually leached from the surface which exposes cellulose and results in the grey surface of wood. However, oil prevents leaching of quinones, hence the dark components remained on the surface and caused the dark colour of wood. Alternatively, dark colour could be a result of the blue staining, but this is unlikely during artificial weathering due to the high dosage of UV radiation.

While the regionally important Istrska belica olive has about double the biophenol content compared to other commercial varieties like Leccino (Butinar et al. 2006), it is believed that the approach presented in this study could be applied to other important olive varieties and warrants further investigation.

\section{Conclusion}

Lampante oil from the Istrska belica olive was chemically modified using two maleinisation treatments. The treatment methods increased the potential for the oil to react with the hydroxyl groups within the wood structure, making them theoretically more viable for wood protection. Leaching of the treatment oils was relatively low compared with other experiments and beech wood specimens treated with DM showed low mass losses. In addition, it was found that the oils were not completely removed from the wood after solvent extraction indicating that they could potentially be used as an immobilisation agent in combination with other treatments thereby reducing the amount of active component of the protective agent.

In future work, a lower amount of impregnated oil will be used to more accurately assess the performance of these modified oils in relation to leaching and fungi performance in wood. It is believed that excessive treatment material present in the wood specimens and the free oils in the lumens were dictating the performance rather than oil bonded to the cell wall. It is also believed that these free oils also resulted in unexpected colour changes, darkening the specimens with quinone compounds. Analysis of these specimens with FTIR would help confirm the presence of quinone compounds. In addition, market-available oil treatments and modified oils from other agricultural residues will be tested for comparison.

The results from this paper have generated interest from local industries, researchers, and more avenues of research in wood protection that utilise low-value agricultural residues. With increased pressure to adopt the circular economy strategy and economic benefits to strengthening value chains, local olive mill collaborators are excited to continue research in this field.

Acknowledgements The authors graciously thank COST Actions FP1303 and FP1407, the IO-0035 Slovenian Infrastructural program for their funding and support and the European Commission for funding the InnoRenew CoE project (Grant Agreement \#739574) under the Horizon 2020 Widespread-Teaming program. The authors also thank and acknowledge the technical support of Primož Habjan, Courtney Williamson, and Marko Posavčević.

Open Access This article is distributed under the terms of the Creative Commons Attribution 4.0 International License (http://creativeco mmons.org/licenses/by/4.0/), which permits unrestricted use, distribution, and reproduction in any medium, provided you give appropriate credit to the original author(s) and the source, provide a link to the Creative Commons license, and indicate if changes were made.

\section{References}

Alfredsen G, Flæte P, Temiz A, Eikenes M, Militz H (2004) Screening of the efficacy of tall oils against wood decaying fungi. In: International research group on wood protection, Document no: IRG-WP 04-30354, Ljubljana, Slovenia, 16-10 June 2004

Aparicio R, Harwood J (2013) Handbook of olive oil, 2nd edn. Springer, Berlin

Borgin K, Corbett K (1970) The stability and weathering properties of wood treated with various oils. Paint Rubber 14:69-72

Bravery AF (1980) A miniaturised wood-block test for the rapid evaluation of wood preservative funcicides. In: Screening techniques 
for potential wood preservative chemicals. Peebles, Scotland, pp 57-65

Burnard MD, Schwarzkopf M, Tverezovskiy V, Treu A, Humar M, Kutnar A (2018) Wood preservatives utilizing low-value olive oil production by-products: analysis. Zenodo. https://doi.org/10.5281/ zenodo. 1248463

Butinar B, Bučar-Miklavčič M, Lipnik-Štangelj M (2006) Antioxidants in virgin olive oils produced from two olive cultivars of Slovene Istria. Ann Ser Hist Nat 16:201-208

Cicerale S, Lucas LJ, Keast RSJ (2012) Antimicrobial, antioxidant and anti-inflammatory phenolic activities in extra virgin olive oil. Curr Opin Biotechnol 23:129-135. https://doi.org/10.1016/j.copbi o.2011.09.006

EN 927-6 (2006) Paints and varnishes - coating materials and coating systems for exterior wood-part 6: exposure of wood coatings to artificial weathering using fluorescent UV lamps and water. Eur Stand

Habicht J, Häntzschel D, Wittenzellner J (2003) Influence of the fixation and ageing procedures on the leaching behaviour of copper from selected wood preservatives in laboratory trials. In: International research group on wood protection, Document no: IRG/ WP 03-20264, Brisbane, Queensland, Australia, 18-23 May 2003

Hon DN-S, Shiraishi N (eds) (2001) Wood and cellulosic chemistry, 2nd edn. Marcel Dekker, New York

Hussain A, Shrivastav A, Jain SK (2013) Antifungal activity of essential oils against local wood degrading cellulolytic filamentous fungi. Adv Biores 4:161-167

Jemai H, Bouaziz M, Fki I, El Feki A, Sayadi S (2008) Hypolipidimic and antioxidant activities of oleuropein and its hydrolysis derivative-rich extracts from Chemlali olive leaves. Chem Biol Interact 176:88-98. https://doi.org/10.1016/j.cbi.2008.08.014

Kiritsakis K, Kontominas MG, Kontogiorgis C, Hadjipavlou-Litina D, Moustakas A, Kiritsakis A (2010) Composition and antioxidant activity of olive leaf extracts from Greek olive cultivars. J Am Oil Chem Soc 87:369-376. https://doi.org/10.1007/s1174 6-009-1517-x

Korukluoglu M, Sahan Y, Yigit A (2008) Antifungal properties of olive leaf extracts and their phenolic compounds. J Food Saf 28:76-87. https://doi.org/10.1111/j.1745-4565.2007.00096.x

Liibert L, Treu A, Meier P (2011) The fixation of new alternative wood protection systems by means of oil treatment. Mater Sci 17:402406. https://doi.org/10.5755/j01.ms.17.4.777

Meyer L, Brischke C, Treu A, Larsson-Brelid P (2016) Critical moisture conditions for fungal decay of modified wood by basidiomycetes as detected by pile tests. Holzforschung 70:331-339. https ://doi.org/10.1515/hf-2015-0046

Meyer-Veltrup L, Brischke C, Alfredsen G, Humar M, Flate PO, Isaksson T, Larsson PB, Westin M, Jermer J (2017) The combined effect of wetting ability and durability on outdoor performance of wood: development and verification of a new prediction approach. Wood Sci Technol 51:615-637. https://doi.org/10.1007/s0022 6-017-0893-x

Mosiewicki M, Aranguren MI, Borrajo J (2005) Mechanical properties of linseed oil monoglyceride maleate/styrene copolymers. J Appl Polym Sci 97:825-836. https://doi.org/10.1002/app.21790
Paajanen L, Ritschkoff AC (2002) Effect of crude tall oil, linseed oil and rapeseed oil on the growth of the decay fungi. In: International research group on wood protection, 33rd Annual Meeting in Cardiff, Document no: IRG/WP 02-30299, Wales, United Kingdom, 12-17 May 2002

R Core Team (2017) R: a language and environment for statistical computing. Version 3.4.1. R Foundation for Statistical Computing, Vienna

Raspor P, Smole-Možina S, Podjavoršek J, Pohleven F, Gogala N, Nekrep FV, Hacin J (1995) ZIM: zbirka industrijskih mikroorganizmov-Collection of industrial microorganisms. Kat biokult Cat Cult 98

RStudio Inc (2017) RStudio: Integrated development for R. Version 1.0.153

Stark AH, Madar Z (2002) Olive oil as a functional food: epidemiology and nutritional approaches. Nutr Rev 60:170-176. https://doi. org/10.1301/002966402320243250

Swaboda C, Fischer M, Jacobs K (2016) Development of a new method for wood hydrophobizing and fixation of copper compounds by chemical hardening of vegetable based modified oils. In: International research group on wood protection, 47th annual meeting, Document no: IRG/WP 16-40754, Lisbon, Portugal, 15-19 May 2016

Temiz A, Akbas S, Panov D, Terziev N, Alma MH, Parlak S, Kose G (2013) Chemical composition and efficiency of bio-oil obtained from giant cane (Arundo donax L.) as a wood preservative. BioResources 8:2084-2098. https://doi.org/10.15376/biore s.8.2.2084-2098

Terziev N, Panov D (2010) Plant Oils As "Green" substances for wood protection. In: 4th international conference on environmentallycompatible forest products. At Porto, Portugal, pp 143-149

Tomak E, Hughes M, Yildiz U, Viitanen H (2011) The combined effects of boron and oil heat treatment on beech and Scots pine wood properties. Part 1: boron leaching, thermogravimetric analysis, and chemical composition. J Mater Sci 46:598-607. https:// doi.org/10.1007/s10853-010-4859-8

Treu A, Lückers J, Militz H (2004) Screening of modified linseed oils on their applicability in wood protection. In: International research group on wood protection, Document no: IRG/WP 04-30346, Ljubljana, Slovenia, 16-20 June 2004

Treu A, Larnøy E, Militz H (2011) Process related copper leaching during a combined wood preservation process. Eur J Wood Prod 69:263-269. https://doi.org/10.1007/s00107-010-0427-9

Wickham H (2009) ggplot2: elegant graphics for data analysis. Springer, New York

Publisher's Note Springer Nature remains neutral with regard to jurisdictional claims in published maps and institutional affiliations. 